\title{
CONVERSAS APÓS UMA DÉCADA DA IMPLANTAÇÃO DOS INSTITUTOS FEDERAIS
}

\author{
Marcelina Teruko Fujii Maschio \\ Instituto Federal de Mato Grosso do Sul \\ DOI: 10.15628/rbept.2019.7998
}

Artigo submetido em nov/2018 e aceito em jun/2019

\begin{abstract}
RESUMO
O relato aqui exposto busca realizar um resgate informal do momento em que os Institutos Federais de Educação, Ciência e Tecnologia foram criados pela Lei oㅜ 11.892 de 2008. Tem por objetivo retratar brevemente a presença da Educação Profissional nas legislações educacionais ao longo dos séculos XX e XXI. Apresenta o cenário do que ocorria nas instituições que passaram a compor a rede de federal de educação profissional e tecnológica, no momento que antecedeu a promulgação da lei de criação. Retrata algumas atividades, necessárias para a implantação das instituições. Este relato baseia-se em impressão pessoal, de cunho empírico, tendo como fonte conversas entre aqueles que assumiram o protagonismo de vivenciar os desafios impostos na implantação desta rede.
\end{abstract}

Palavras-Chave: Institutos Federais. Rede federal de educação profissional. tecnológica.

\section{CONVERSATIONS AFTER A DECADE OF THE IMPLEMENTATION OF THE FEDERAL INSTITUTES}

\begin{abstract}
The report presented here seeks to provide an informal rescue of the moment when the Federal Institutes of Education, Science and Technology were created by Law No. 11,892 of 2008. Its objective is to briefly portray the presence of Vocational Education in educational legislation throughout the 20th and XXI. It presents the scenario of what happened in the institutions that started to compose the federal network of professional and technological education, in the moment that preceded the promulgation of the law of creation. It portrays some activities, necessary for the implantation of the institutions. This report is based on personal impression, empirical, having as an source conversations among those who took the leading role of experiencing the challenges imposed in the implementation of this network.
\end{abstract}

Keywords: Federal Institutes. federal network of professional. technological education. 


\section{APRESENTAÇÃO}

Reúno aqui histórias lidas, ouvidas, vividas para então, contar um pouco da minha relação, e a de muitos, com os Institutos Federais de Educação, Ciência e Tecnologia. Pode-se contar uma história baseada em uma sequência cronológica, ou do que considerar mais relevante para a ocasião, ou optar pelos fatos que destacaram quando tentamos vasculhar as memórias ou simplesmente conversar sobre nosso "caso de amor pedagógico" com esta instituição que escolhemos para chamar de "nossa".

Ao pensar no tempo histórico, o objetivo seria analisar os impactos de percepções ocorridos em determinado período, cientes de que uma década é pouco para que os resultados possam afirmar verdades ou conclusões ao se tratar de programas de longo prazo, como os educacionais. Então prevalecerá neste diálogo, reflexões, intenções, vontades e momentos vivenciados pelos "pioneiros" desta institucionalidade, chamada aqui carinhosamente de IF.

No período de 2008 a 2018 dos 38 Institutos Federais de Educação, Ciência e Tecnologia, buscamos indicadores para refletir sobre percepções e avaliar sobre esta década vivida. Alguns Institutos com uma trajetória centenária, que são aqueles originalmente oriundos das 19 Escolas de Aprendizes e Artífices criadas em 1909, outros, mais jovens, como é o caso daqueles que entraram em funcionamento após a lei de criação № 11.892 em 2008.

Parece que este tempo é insuficiente para realizar uma análise criteriosa dos impactos da implantação de uma instituição de educação cujos reflexos são de longo prazo, mas a sensação para os Institutos Federais é de este tempo passou rápido. Foi o momento para que pudéssemos organizar, regulamentar e implantar o que havíamos previsto, que demonstrou ser "longo", de múltiplas atividades para em funcionamento, para alguns, e para outros, para que fosse mantida as ofertas educacionais com a mesma qualidade já alcançada. Intenso para dar conta da rápida expansão que ora se apresentava, sejam em números de campi, de estudantes matriculados ou de cursos.

Falo de um lugar, de um dos estados que não possuía a presença da Rede Federal de Educação Profissional, que é o estado de Mato Grosso do Sul. A busca por locais para iniciar as atividades em instalações provisórias, até as obras estivessem concluídas, das compras de mobiliários administrativos e pedagógicos, veículos, equipamentos para os laboratórios. Ainda, de buscar a realização de concursos públicos para servidores, além dos processos de ingresso de estudantes.

Demandas surgiam, como a responsabilidade de elaboração do Termo de Acordo e Metas - TAM, bem como do primeiro Plano de Desenvolvimento Institucional - PDI. Deixar de elaborar os Projetos Políticos Institucionais - PPP, afetos à escola básica, para elaborar então nossos Projetos Pedagógicos Institucionais - PPI. 
Definir bases e princípios, conceitos fundantes teórico-metodológico para que a prática não recaísse em um vazio conceitual. Elaborar documentos norteadores, como regulamentos de organização didáticopedagógica, e outras diretrizes basilares para a elaboração dos Planos Pedagógicos dos Cursos - PPCs. Somados ainda à necessidade de condução de audiências públicas para a indicação de ofertas de eixos tecnológicos e cursos, para os que estavam literalmente "nascendo", sendo implantados do zero e se fazer conhecido nos municípios e na região.

Assim, passados 10 anos, é realmente chegada a hora de avaliar o que fora proposto no Art. 6으 da Lei no 11.892 de 2008.

Art. 6응 Institutos Federais têm por finalidades e características:

I - ofertar educação profissional e tecnológica, em todos os seus níveis e modalidades, formando e qualificando cidadãos com vistas na atuação profissional nos diversos setores da economia, com ênfase no desenvolvimento socioeconômico local, regional e nacional;

II - desenvolver a educação profissional e tecnológica como processo educativo e investigativo de geração e adaptação de soluções técnicas e tecnológicas às demandas sociais e peculiaridades regionais;

III - promover a integração e a verticalização da educação básica à educação profissional e educação superior, otimizando a infraestrutura física, os quadros de pessoal e os recursos de gestão;

IV - orientar sua oferta formativa em benefício da consolidação e fortalecimento dos arranjos produtivos, sociais e culturais locais, identificados com base no mapeamento das potencialidades de desenvolvimento socioeconômico e cultural no âmbito de atuação do Instituto Federal;

$V$ - constituir-se em centro de excelência na oferta do ensino de ciências, em geral, e de ciências aplicadas, em particular, estimulando o desenvolvimento de espírito crítico, voltado à investigação empírica;

VI - qualificar-se como centro de referência no apoio à oferta do ensino de ciências nas instituições públicas de ensino, oferecendo capacitação técnica e atualização pedagógica aos docentes das redes públicas de ensino;

VII - desenvolver programas de extensão e de divulgação científica e tecnológica;

VIII - realizar e estimular a pesquisa aplicada, a produção cultural, o empreendedorismo,

o cooperativismo e o desenvolvimento científico e tecnológico;

IX - promover a produção, o desenvolvimento e a transferência de tecnologias sociais, notadamente as voltadas à preservação do meio ambiente.

O presente texto não pretende configurar-se como projeto de pesquisa, com metodologias, formas de coleta e de análise dos dados, para 
avaliar o impacto desta política pública, que poderá ser a etapa seguinte a esta conversa. Pensar coletivamente, porém com atuação local, seria parte indissolúvel da proposta que ora se apresenta.

Ao concordar que há muitos "Brasis" no nosso país, com características e peculiaridades próprias, e apesar de os Institutos Federais serem fruto de uma política nacional, aqui será defendida a ideia de um olhar regional e local, seja em âmbito de município, micro ou mesorregião. Lembrar que cada campus, cada Instituto Federal é único, com histórias e desafios próprios, além de respeitar a trajetória e características das pessoas que lá atuam ou atuaram.

Como atestar nossa efetividade como instituição pública, refletir sistematicamente sobre os impactos sociais, culturais, produtivos decorridos da atuação dos Institutos Federais e das demais instituições que compõem esta Rede Federal de Educação Profissional, Científica e Tecnológica RFEPCT, nos municípios e no entorno. Levantar indicadores para que possamos verificar o cumprimento dos objetivos previstos na lei de criação, acentuando a relação dialógica que permita a participação social, condição indispensável para avaliação das políticas educacionais, de longo prazo.

Adotar a sinergia de força da trama do tecido desta rede, a fim de propor formas e estratégias que possam metodologicamente permitir o acompanhamento, o monitoramento e a avaliação. Analisar a combinação de políticas públicas que permitam convergir para um planejamento efetivo, otimização de recursos e dos resultados almejados para embasar os futuros processos de tomada de decisão.

\section{PRESENCA DA EDUCAÇÃO PROFISSIONAL E TECNOLÓGICA NAS LEGISLAÇŐ́ES EDUCACIONAIS}

Ao longo da caminhada, as instituições de Educação Profissional sofreram várias mudanças, que não se resumiram à mera alteração de nomenclaturas, mas, principalmente dos papéis a serem desempenhados, com os mais distintos objetivos a serem cumpridos, ancorados na relação entre trabalho e educação, nas relações de poder, reflexos de uma sociedade capitalista e desigual.

A Educação Profissional, inicialmente com caráter assistencialista, foi tratada parcialmente nas legislações educacionais brasileiras desde 1909, quando eram destinadas à aprendizagem de ofícios artífices. De acordo com o Decreto no 5.241 de 1927 o ensino profissional era obrigatório nas escolas primárias subvencionadas ou mantidas pela União. A Constituição Federal de 1937 definiu que as indústrias e os sindicatos criassem escolas de aprendizes, baseadas em suas especialidades. Dez anos após, as escolas de aprendizes e artífices foram transformadas em Liceus Industriais.

As leis orgânicas em 1942, definiram que o ensino industrial seria ministrado em dois ciclos: o primeiro, chamado de básico, focava o ensino de mestria, o ensino artesanal e a aprendizagem e o segundo ciclo, compreendia o ensino técnico e o pedagógico. Neste mesmo ano, o Decreto-Lei no 4.127 
extinguiu os Liceus Industriais, transformando-os em Escolas Industriais e Técnicas.

A Constituição de 1946 impôs que as empresas industriais e comerciais ministrassem, em cooperação, cursos de aprendizagem aos seus trabalhadores menores, respeitados os direitos dos professores. Em 1959 as Escolas Industriais e Técnicas foram transformadas em Escolas Técnicas Federais.

Na primeira Lei de Diretrizes e Bases da Educação Nacional - LDB, a Lei no 4.024 de 1961, foi possibilitado aos concluintes de cursos de educação profissional, organizados nos termos das Leis Orgânicas do Ensino Profissional, a continuidade de formação com possibilidade de ingresso no ensino superior.

A Lei Federal ํo 5.692 de 1971 impôs que todo Ensino Médio, à época denominado de ensino de $2^{\circ}$ grau, fosse "profissionalizante". Apesar de alguns cursos atenderem seus objetivos grande parte eram "mascarados" com o nome de curso técnico, porém sem a devida formação ou vinculação com práticas profissionais.

Tal situação perdurou por 11 anos, até 1982 quando a Lei $n^{0} 7.044$ tornou facultativa a vinculação obrigatória do então $2^{\circ}$ grau a um curso técnico. Em 1994, a Lei Federal no 8.948 instituiu o Sistema Nacional de Educação Tecnológica, que deflagrou o processo de transformação das Escolas Técnicas e das Escolas Agrotécnicas Federais, em Centros Federais de Educação Tecnológica (Cefet).

Somente em 1996, na atual LDB no 9.394, a Educação Profissional ganhou, um capítulo próprio, o Capítulo III do Título V —Dos níveis e das modalidades de educação e ensino. Entretanto, em 1997, o Decreto n. o 2.208 que veio regulamentar os Arts. 39 a 41 desta lei, vetou a integração entre a Educação Básica e a Educação Profissional. Este decreto foi responsável por grande parte do esfacelamento e desmonte das instituições, devido ser esta a especialidade das instituições, além do grande número de docentes vinculados às unidades curriculares da Educação Básica

A Portaria no 646 de 1997, permitiu que as instituições federais de educação tecnológica pudessem manter a oferta de Ensino Médio, com matrícula independente da educação profissional. Determinou também a necessidade de as instituições elaborarem um Plano de Implantação, para cumprimento das diretrizes contidas no famigerado Decreto n. 02.208 num prazo de quatro anos.

Este período após a publicação da LDB foi marcado por reformas na educação, em geral, financiadas por organismos internacionais. Ainda, por força do Decreto no 2.208, foi implementado o Programa de Reforma da Educação Profissional - Proep, pela Portaria n. $\stackrel{0}{1.005}$ de 1997 financiado com $25 \%$ de dotações orçamentárias do MEC, 25\% do Fundo de Amparo ao Trabalhador do Ministério do Trabalho e Emprego, MTE e 50\% de empréstimo do Banco Interamericano de desenvolvimento - BID. Tinha por objetivo firmar parcerias com segmentos comunitários e os estados para a oferta de Educação Profissional. Previa financiamento de obras, aquisição de equipamentos e capacitação de pessoas. Poucos êxitos foram obtidos deste 
programa, sendo que algumas das instituições do Proep, foram destinadas posteriormente aos Institutos Federais.

Tal situação permaneceu até 2004, que com a publicação do Decreto no 5154 que permitiu o retorno da integração da Educação Básica à Educação Profissional, além de apresentar algumas possibilidades, como saídas intermediárias e a obtenção de certificados de qualificação para o trabalho após sua conclusão com aproveitamento.

Em 2007 foi publicado o Decreto no 6.302, que trata do Programa Brasil Profissionalizado, a fim de subsidiar financeiramente ações de infraestrutura e desenvolvimento para ampliação e modernização das escolas das redes estaduais de Educação Profissional. Tinha a finalidade de expandir e ampliar a oferta de cursos técnicos de nível médio, principalmente do ensino médio integrado à educação profissional e tecnológica.

Em 2008 a Educação Profissional ganha mais um adjetivo pela Lei no 11.741 agora denominada Educação Profissional e Tecnológica na atual LDB. Neste mesmo ano, foi instituído o Catálogo Nacional de Cursos Técnicos CNCT.

Em 2011 o Decreto № 12.513 que estabeleceu o Programa Nacional de Acesso ao Ensino Técnico e Emprego (Pronatec) e do Bolsa Formação. Estes programas, sob a ótica de algumas instituições da rede federal, poderiam fortalecer as ações dos Institutos Federais caso fossem incorporadas às suas dotações orçamentárias, para as aquisições previstas pelo programa, ainda que fosse possível contratações de pessoas, mesmo que temporárias. Caso fossem executadas pela força de trabalho das institucional, e não como ações complementares, realizadas externas à carga horária dos servidores ou como apêndices aos projetos educacionais, poderiam fortalecer e não sombrear as ações institucionais. Acrescentem-se os mesmos apontamentos para o Mediotec, que acabam por fragilizar e vulnerabilizar a adesão aos referidos programas.

A Lei no 13.005 de 2014 que aprovou o Plano Nacional de Educação - PNE apresentou metas importantes e desafiadoras à Educação Profissional e Tecnológica no que se refere a oferecer, no mínimo, $25 \%$ (vinte e cinco por cento) das matrículas de educação de jovens e adultos, nos ensinos fundamental e médio, na forma integrada à educação profissional". Também trouxe o desafio de triplicar as matrículas da educação profissional técnica de nível médio, assegurando a qualidade da oferta e pelo menos $50 \%$ (cinquenta por cento) da expansão no segmento público.

Estes desafios são acentuados pela Lei no 13.415 de 2017 que trata da reforma do Ensino Médio, bem como a Base Nacional Curricular Comum que não coadunam com os objetivos previstos na lei de criação dos Institutos Federais.

\section{CENÁRIO NACIONAL NO MOMENTO DA CRIAÇÃO DOS INSTITUTOS FEDERAIS}


Os Institutos Federais "nascem" após um período de estagnação de quase 10 anos, regulada pela Lei no 9.649 de 1998 que vetava a expansão do sistema federal de Educação Profissional, exceto se realizada em parcerias, conforme Art. 47, parágrafo $5^{\circ}$, descrito abaixo:

§ 50 A expansão da oferta de educação profissional, mediante a criação de novas unidades de ensino por parte da União, somente poderá ocorrer em parceria com Estados, Municípios, Distrito Federal, setor produtivo ou organizações não-governamentais, que serão responsáveis pela manutenção e gestão dos novos estabelecimentos de ensino.

Este momento foi considerado de extrema "crise" desta rede, sem previsão de contratações de servidores, sem investimentos, inclusive com custeio insuficiente para manutenção das instituições. A situação que vetava a abertura de instituições por parte do governo perdurou até 2005, com a publicação da Lei n. ㅇ 11.195 que permitiu retomar a instalação de novas instituições de educação profissional e tecnológica

Em 2007 o país começa a vivenciar uma prospecção de expansão e reestruturação. No caso das universidades federais, foram demandadas pelo Programa de Apoio a Planos de Reestruturação e Expansão das Universidades Federais - Reuni, instituído pelo Decreto № 6.096, como uma das ações do Plano de Desenvolvimento da Educação - PDE. Este programa tinha como foco a interiorização, em conjunto com a oferta de cursos de formação de professores, ampliação de vagas nos cursos existentes, inovação e novos formatos de cursos de graduação.

No cenário da Educação Profissional, foi o Decreto n 6.095 que impulsionou a expansão, ao estabelecer diretrizes para o processo de reorganização das instituições federais de educação tecnológica, para fins de constituição dos Institutos Federais de Educação, Ciência e Tecnologia no âmbito da Rede Federal, ainda denominadas de Ifets, sigla que depois fora abandonada para se tornar IFs.

Assim, surge a proposta às instituições federais de Educação Profissional em integrar-se a uma nova configuração organizacional, ou seja, serem transformadas e/ou agregadas em Institutos Federais. Neste cenário, de acordo com dados da Secretaria de Educação Profissional do Ministério da Educação Setec/MEC, a rede federal, naquele momento de implantação da Proposta de Política Pública de Educação Profissional e Tecnológica, era composta de 34 Centros Federais de Educação Tecnológica, 36 Escolas Agrotécnicas Federais, 01 Escola Técnica Federal, 30 Escolas Técnicas vinculadas a Universidades Federais e 42 Unidades de Ensino Descentralizadas.

Otranto (2010) aponta que, entre as 102 instituições que poderiam optar, 75 aderiram à proposta. A autora, as 36 Escolas Agrotécnicas Federais existentes naquele momento aderiram; e que das 32 escolas vinculadas a 21 Universidades Federais, apenas 8 optaram pela adesão, a Escola Técnica Federal do Tocantins, bem como os todos os 32 Cefets, dos 34 existentes, 
ressaltando a exceção do Cefet-MG e o Cefet-RJ. Aqui cabe destacar que estes foram as primeiras instituições transformadas em Cefet em 1978, juntamente com o Cefet-PR. Como em 2005 houve a transformação do CefetPR, na primeira Universidade Tecnológica do Brasil, MG e RJ não aderiram à proposta dos IFs, por terem características muitos semelhantes ao Cefet-PR, o que possibilitaria uma futura mudança de institucionalidade.

A implantação dos IF deu-se gradativamente, dividida em três fases. De acordo com os dados do Relatório do Tribunal de Contas da União (TCU, 2012), a Fase I ocorreu de 2003 a 2010, a Fase II de 2011 a 2012 e a Fase III de 2013 a 2014. Já o MEC dividiu estas mesmas fases, considerando prerrogativas e medidas adotadas para a implantação, considerando a Fase I de 2005 a 2007, a Fase II teve início em 2007 e a Fase III com início em 2011.

A Fase I, segundo o MEC, teve como prioridade foi construir 5 Escolas Técnicas Federais; 4 Escolas Agrotécnicas Federais, além de 33 novas Unidades de Ensino Descentralizadas - Uneds. Previa a necessidade de aporte de recursos financeiros, a memória de cálculo para estabelecimento do custo de implementação de cada unidade, a necessidade de criação de cargos efetivos docentes e de técnicos-administrativos.

A Fase II teve a previsão de 150 novas instituições federais em localidades escolhidas pelo MEC, por manifestação dos municípios por meio da Chamada pública MEC/SETEC n. $.001 / 2007$ para propostas para apoio ao plano de expansão da rede federal de educação tecnológica. De acordo com MEC (2007), a definição das localidades contempladas orientou-se por uma abordagem multidisciplinar, fundamentada em análise crítica de variáveis geográficas, demográficas, socioambientais, econômicas e culturais, com destaque para as seguintes finalidades:

a) distribuição territorial equilibrada das novas unidades de ensino;

b) cobertura do maior número possível de mesorregiões em cada Unidade da Federação;

c) proximidade das novas unidades de ensino aos Arranjos Produtivos Locais instalados e em desenvolvimento; d) interiorização da oferta pública de educação profissional e de ensino superior;

e) redução dos fluxos migratórios originados nas regiões interioranas com destino aos principais centros urbanos;

f) aproveitamento de infraestruturas físicas existentes e

g) identificação de potenciais parcerias.

Em 2008 foi publicado o resultado desta Chamada Pública pela Portaria MEC/SETEC no 116, em 2008. Ainda neste ano foi encaminhado o Projeto de Lei no 3.775 que propunha a criação dos IFs, da Rede Federal de EPCT, bem como o documento "Concepções e Diretrizes dos Institutos Federais de Educação, Ciência e Tecnologia". A Fase II apresentou 150 
cidades a serem contempladas com um campus. Á partir de 2011 a Fase III previu a criação de mais 208 novas unidades.

Assim, algumas instituições centenárias (ou próximas a isto), após a decisão de aderir à nova reorganização da rede federal, aos Institutos Federais, tiveram que rever as tarefas cotidianamente executadas, agora com outras roupagens e novos objetivos incorporados. Eram autarquias com Diretor-Geral, partícipes de Conselhos próprios em âmbito nacional, como o Conselho de Dirigentes dos Centros Federais de Educação Tecnológica Concefet, Conselho de Escolas Agrotécnicas Federais - Coneaf e Conselho Nacional de Dirigentes de Escolas Técnicas vinculadas às Universidades Federais - Condetuf, entre outros. Além de vivenciar à recente vinculação a uma Reitoria, inexistente até então, além do modelo multicampi.

As Instituições possuíam características e culturas organizacionais distintas e formas próprias de gestão. Servidores há mais tempo na rede federal, recepcionavam novos técnicos-administrativos e docentes. Salientase que ao optar pela transformação, acabaram por "desapegar" de parte de sua identidade construída ao longo do tempo, presentes em suas logomarcas, cores, bandeiras e até hinos em alguns casos.

Ao adotar um novo nome, com características de atuação bastante diversificadas, passaram a ser parte de uma Rede Federal de Educação Profissional e Tecnológica, que completaria seu centenário em 2009. Uma rede que nasceu grande, com aproximadamente 400 campi, sendo considerada uma das maiores redes de educação do país. E assim, sejam por fusão, transformação, criação, nasceram os 38 Institutos Federais, com capilaridade e presença em todos estados da federação, sejam nas capitais, nos grandes centros urbanos, próximas ao litoral ou não, inclusive municípios menores, que 30 mil habitantes.

E os desafios se apresentavam, ora na oferta de cursos em diversos níveis e modalidades, desde a qualificação até a pós-graduação, ora pelo reforço na atuação em pesquisa e extensão. Porém, mesmo sabendo que estas características não eram totalmente novas, pois os então Cefets já atuavam neste modelo.

Porém, diferentemente dos Cefets, os institutos foram implantados para atender aos locais que naquela época, poderia ser inimaginável possuir uma Instituição Federal de Educação Profissional. Interiorizar, que parecia ser apenas uma característica inerente aos Institutos Federais, continuou a se apresentar como um grande desafio. Um outro desafio foi a equiparação às universidades no que se refere à regulação dos cursos superiores, sendo necessário adequar-se para o credenciamento, o recredenciamento e as avaliações de cursos junto ao Inep.

Outro desafio da implantação foi o tempo acelerado da expansão, cujo tempo político difere do tempo necessário para a implantação, sem que ainda tivéssemos dado conta de finalizar o que já havia sido iniciado, como concluir adequadamente infraestrutura necessária, laboratórios e equipamentos didáticos-pedagógicos, além de acervo bibliográfico. 
Otranto (2011, p. 12-13) assevera que a expansão e a verticalização trouxeram em seu bojo a reconfiguração da educação profissional e tecnológica:

\begin{abstract}
Em sua grande maioria, as escolas profissionalizantes, não estavam preparadas para a transformação em Instituições de educação superior, multicampi, com todas as funções, direitos e deveres de uma universidade, com oferecimento da graduação, licenciatura e pós-graduação, atividades de pesquisa e extensão, além de outras não exigidas para as universidades, mas obrigatórias para os Institutos Federais, tais como: o ensino médio, técnico e educação de jovens e adultos.
\end{abstract}

Este cenário era composto também por servidores que participaram de mais de uma mudança de institucionalidade, adentraram quando Escola Técnica, e participaram tanto da transformação em Cefet, como em Instituto Federal. Da dificuldade de reflexão entre aqueles que optam por um modelo que se assemelha mais às universidades, e em contraponto aqueles que buscam a manutenção das características de uma escola técnica. Precisamos definir qual a densidade, como efetivar o que nos caracteriza e nos identifica referencialmente como Institutos Federais.

\title{
4 REFLEXÕES FINAIS
}

E assim, terminamos nossa "breve" conversa pensando nos desafios que ora se apresentam para os próximos anos, na qual intensas mudanças previstas, como as diretrizes para o Ensino Médio, da respectiva aprovação da Base Nacional Curricular Comum, da eleição de presidência do país que iniciará o ano de 2019 com novas equipes e visões de educação.

Colocar à tona os indicadores e dados desta rede, a fim de demonstrar quais são os resultados obtidos e os impactos desta política pública para a sociedade, para consolidar as finalidades e objetivos previstos no momento da criação. Refletir para que, se necessário, possamos fazer correções de rumos ou redirecionamentos de ações para que possamos cumprir nossa missão.

Intensificar relacionamentos para fortalecer as tramas desta rede federal de Educação Profissional e Tecnológica, para que possamos fundir forças, buscar nesta teia a sinergia, para reforçar o papel social dos Institutos Federais, do que nos caracteriza como instituição pública.

\section{REFERÊNCIAS}

BRASIL Lei 13.415, de 16 de fevereiro de 2017. Altera as Leis no 9.394, de 20 de dezembro de 1996, que estabelece as diretrizes e bases da educação nacional, e 11.494, de 20 de junho 2007 e institui a Política de Fomento à 
Implementação de Escolas de Ensino Médio em Tempo Integral. Diário Oficial [da] República Federativa do Brasil. Seção 1 de 17/2/2017, Página 1.

Chamada Pública MEC/SETEC n. ํ 001/2007. Chamada pública de propostas para apoio ao Plano de Expansão da Rede Federal de Educação Tecnológica. Diário Oficial [da] República Federativa do Brasil. Seção 3 de 27/04/2007, Página 59.

Constituição da República dos Estados Unidos do Brasil, decretada pelo Presidente da República em 10.11.1937. Diário Oficial [da] República Federativa do Brasil. Seção 1 de 10/11/1937, Página 22359.

Constituição de 1946. Constituição dos Estados Unidos do Brasil, decretada pela Assembleia Constituinte publicado no Diário Oficial [da] República Federativa do Brasil. Seção 1 de 19/09/1946.

Constituição Federal de 1937. Constituição da República dos Estados Unidos do Brasil, decretada pelo Presidente da República em 10.11.1937. Diário Oficial [da] República Federativa do Brasil. - Seção 1 de10/11/1937, Página 22359.

Decreto Federal $\mathrm{n} \cong 2.208$, de 17 de abril de 1997. Regulamenta o $\S$ $2^{\circ}$ do art. 36 e os arts. 39 a 42 da Lei no 9.394 , de 20 de dezembro de 1996, que estabelece as diretrizes e bases da educação nacional. Diário Oficial [da] República Federativa do Brasil. Seção 1 de 18/4/1997, Página 7760.

Decreto $n . \circ 5.154$, de 23 de julho de 2004. Regulamenta o $\S 2^{\circ}$ do art. 36 e os arts. 39 a 41 da Lei no 9.394 de 20 de dezembro de 1996, que estabelece as diretrizes e bases da educação nacional, e dá outras providências. Diário Oficial [da] República Federativa do Brasil. Seção 1 de 26/7/2004, Página 18.

. Decreto $n^{0}$ 1.606, de 29 de dezembro de 1906. Crea uma Secretaria de Estado com a denominação de Ministerio dos Negocios da Agricultura, Industria e Commercio. Diário Official - 3/1/1907, Página 65.

Decreto no 12.513, de 26 de outubro de 2011. Instituiu o Programa Nacional de Acesso ao Ensino Técnico e Emprego (Pronatec) e do Bolsa Formação. Disponível em:< http://www.planalto.gov.br/ccivil_03/_ato20112014/2011/lei/l12513.htm>. Acesso em: 20 nov. 2018.

Decreto $n^{0} 5.241$ de 22 de agosto de 1927. Crêa o ensino profissional obrigatório nas escolas primarias subvencionadas ou mantidas pela União, bem como no Colégio Pedro II e estabelecimentos a este equiparados e dá outras providencias. Diário Oficial [da] República Federativa do Brasil. Seção 1 de 26/8/1927, Página 18653.

Decreto no 5.840, de 13 de julho de 2006. Disponível em: < http://www.planalto.gov.br/ccivil_03/_ato2004-

2006/2006/decreto/D5840.htm>. Acesso em: 21 nov. 2018.

Decreto $n^{\circ}$ 6. 095, de 24 de abril de 2007. Estabelece diretrizes para o processo de integração de instituições federais de educação tecnológica, para fins de constituição dos Institutos Federais de Educação, Ciência e 
Tecnologia - IFET, no âmbito da Rede Federal de Educação Tecnológica. Diário Oficial da União. Seção 1 de 25/4/2007, Página 6.

Decreto no 6. 096, de 24 de abril de 2007. Institui o Programa de Apoio a Planos de Reestruturação e Expansão das Universidades Federais REUNI. Disponível em: http://www.planalto.gov.br/ccivil_03/_ato20072010/2007/decreto/d6096.htm.

Decreto no 6.095, de 24 de abril de 2007. Disponível em: <http://www.planalto.gov.br/ccivil_03/_ato2007-

2010/2007/decreto/d6095.htm>. Acesso em: 3 mar. 2014.

Decreto no 6.302, de 12 de dezembro de 2007. Institui o Programa Brasil Profissionalizado. Diário Oficial [da] República Federativa do Brasil. Seção 1 de 13/12/2007, Página 4.

Decreto $n^{\circ}$ 7.566, de 23 de setembro de 1909. Crêa nas capitaes dos Estados da Republica Escolas de Aprendizes Artifices, para o ensino profissional primario e gratuito. Diário Official - 26/9/1909, Página 6975.

Decreto-Lei no 4.127 de 25 de fevereiro de 1942. Estabelece as bases de organização da rede federal de estabelecimentos de ensino industrial. Diário Oficial [da] República Federativa do Brasil. Seção 1 de 27/2/1942, Página 2957.

Decreto-Lei n4.073 de 30 de janeiro de 1942. Lei Orgânica do ensino Industrial. Diário Oficial [da] República Federativa do Brasil. Seção 1 de 9/2/1942, Página 1997.

Lei Federal no 8.984 de 08 de dezembro de 1994. Dispõe sobre a instituição do Sistema Nacional de Educação Tecnológica e dá outras providências. Diário Oficial [da] República Federativa do Brasil. Seção 1 de 9/12/1994, Página 18882.

Lei no 11.534, de 25 de outubro de 2007.Dispõe sobre a criação de Escolas Técnicas e Agrotécnicas Federais e dá outras providências. Diário Oficial [da] República Federativa do Brasil. Seção 1 de 30/12/2008, Página 1.

Lei $\mathrm{n}^{\circ} 11.741$ de 16 de julho de 2008. Altera dispositivos da Lei $\mathrm{n}$ ำ $\overline{9.394}$, de 20 de dezembro de 1996, que estabelece as diretrizes e bases da educação nacional, para redimensionar, institucionalizar e integrar as ações da educação profissional técnica de nível médio, da educação de jovens e adultos e da educação profissional e tecnológica. Diário Oficial [da] República Federativa do Brasil. Seção 1 de 17/7/2008, Página 5.

Lei no 11.892, de 29 dezembro de 2008. Institui a Rede Federal de Educação Profissional, Científica e Tecnológica, cria os Institutos Federais de Educação, Ciência e Tecnologia, e dá outras providências. Diário Oficial [da] República Federativa do Brasil. Seção 1 de 30/12/2008, Página 1.

Lei no 13.005 de 25 de junho de 2014. Aprova o Plano Nacional de Educação - PNE e dá outras providências. Diário Oficial [da] República Federativa do Brasil. Seção 1 - Edição Extra - 26/6/2014, Página 1. 
.. Lei $n^{\circ}$ 4. 024 de 20 de dezembro de 1961. Fixa as Diretrizes e Bases da Educação Nacional. Diário Oficial [da] República Federativa do Brasil. Seção 1 de 27/12/1961, Página 11429.

Lei $n^{0} 5.692$ de 11 de agosto de 1971. Fixa Diretrizes e Bases para o $\overline{\text { ensino }}$ de $1^{\circ}$ e $2^{\circ}$ graus, e dá outras providências. Diário Oficial [da] República Federativa do Brasil. Seção 1 de 12/8/1971, Página 6377.

Lei no 7.044 de 18 de outubro de 1982. Diário Oficial [da] República Federativa do Brasil. Seção 1 de 19/10/1982, Página 19539.

Lei no 9.394, de 20 de dezembro de 1996. Estabelece as diretrizes e bases da educação nacional. Diário Oficial da União Seção 1 de 23/12/1996, Página 27833.

Lei no 9.649, de 27 de maio de 1998. Dispõe sobre a organização da Presidência da República e dos Ministérios, e dá outras providências. Diário Oficial [da] República Federativa do Brasil. Seção 1 de 28/5/1998, Página 5.

SETEC/MEC Portaria no 116 de 31 de março de 2008. Divulga a relação das propostas aprovadas no processo de seleção de que trata o item 6 da Chamada Pública MEC/SETEC no 002/2007, e que pautarão a elaboração do Projeto de Lei de constituição dos Institutos Federais de Educação, Ciência e Tecnologia. Diário Oficial [da] República Federativa do Brasil. 09 abr. 2008.

Chamada Pública MEC/SETEC n. 002/2007. Chamada Pública de Propostas para constituição dos Institutos Federais d e Educação, Ciência e Tecnologia - $\quad$ IFET. Disponível em:< http://portal.mec.gov.br/arquivos/pdf/chamada_publica_ifet.pdf>. Acesso em: 1 mai. 2015.

Portaria no 870, de 16 de julho de 2008. Instituí o Catálogo Nacional de Cursos Técnicos CNCT Diário Oficial [da] República Federativa do Brasil nํ137, sexta-feira, 18 de julho de 2008, seção 1, página 13.

Portaria MEC № 1005/97 de 10 de setembro de 1997. Implementa o Programa de Reforma da Educação Profissional - PROEP. Disponível em:<http://portal.mec.gov.br/setec/arquivos/pdf/PMEC1005_97.pdf>. Acesso em: 30 out. 2018.

Portaria MEC № 646/97 de 14 de maio de 1997. Regulamenta a implantação do disposto nos artigos 39 a 42 da Lei Federal no 9.394/96 e no Decreto Federal no 2.208/97 e dá outras providências (trata da rede federal de educação tecnológica). http://portal.mec.gov.br/setec/arquivos/pdf/PMEC646_97.pdf.

GOERGEN, P. A Avaliação universitária na perspectiva da pós-modernidade, in: Sobrinho e Ristoff. Universidade desconstruída. Florianópolis, Insular, 2000.

OTRANTO, Célia Regina. A Política de Educação Profissional do Governo Lula. In: Anais eletrônicos da 34a Reunião Anual da ANPED, Natal, RN, 2011. 
A reforma da educação superior do governo Lula: da inspiração à implantação. In: SILVA JUNIOR, João dos Reis; OLIVEIRA, João Ferreira de; MANCEBO, Deise. (Org.). Reforma universitária: dimensões e perspectivas. Campinas, SP: Alínea, 2006. p. 43-58.

OTRANTO, Célia Regina. Criação e implantação dos Institutos Federais de Educação, Ciência e Tecnologia - IFETs. In: Revista RETTA (PPGEA/UFRRJ), Ano I, no 1, jan-jun 2010, p. 89-110.

TRIBUNAL DE CONTAS DA UNIÃO. Relatório de auditoria operacional em ações da rede federal de educação profissional, científica e tecnológica.Disponível em: https://portal.tcu.gov.br/lumis/portal/file/fileDownload.jsp?inline=1\&fileld=8A81 82A14D92792C014D92847E5F3E97. Acesso em: 27 out. 2018. 